\title{
Islet cell necrosis in the neonatal pancreas: a report of three cases
}

\author{
P F ROBERTS \\ From the Department of Histopathology, Norfolk and Northwich Hospital
}

SUMMARY Three cases of islet cell necrosis in neonates are reported. The association of this rare condition with antepartum haemorrhage, anoxia, shock and intravascular coagulation are discussed. The clinical and morphological appearances were compared with previous descriptions of this condition and an association with neonatal hypoglycaemia was made. There are several pathophysiological mechanisms which may be responsible for this unusual pattern of necrosis.

Neonatal islet cell necrosis is not described in most standard textbooks of pathology and there have only been a few reported cases. ${ }^{1-3}$

I describe three new cases in detail, discuss the factors associated with this condition, and review previous reports of descriptions of degenerative changes in the islets of Langerhans in the neonatal period.

\section{Case reports}

\section{CASE 1}

A baby boy of 35 weeks' gestation was delivered by caesarian section because of maternal pre-eclamptic toxaemia and placental abruption. At birth the infant weighted $2044 \mathrm{~g}$ and began breathing immediately. The Apgar score was 8 at one minute and 9 at five minutes, the skin was pink in air, and there was no intercostal recession. The pulse was $150 /$ minute. At 24 hours of age abdominal distention, large gastric aspirations, and hypothermia developed. The infant was intubated and ventilated. Rectal bleeding developed and an abdominal radiograph showed necrotising enterocolitis. The haemoglobin concentration was $18.8 \mathrm{~g} / \mathrm{dl}$, white cell count $6.4 \times 10^{9} / 1$, platelets $262 \times 10^{9} / 1$, serum sodium concentration 140 $\mathrm{mmol} / \mathrm{l}$, serum potassium concentration $4.7 \mathrm{mmol} / \mathrm{l}$, and serum urea concentration $3.7 \mathrm{mmol} / \mathrm{l}$. Treatment was started with penicillin, netilmicin, and metronidazole. At 36 hours blood-stained diarrhoea persisted and was accompanied by hypotension (37/23 $\mathrm{mm} \mathrm{Hg})$, with tachycardia (200/minute) and fever of

Accepted for publication 13 March 1987 $38^{\circ} \mathrm{C}$. At 72 hours of age anaemia and slight icterus developed, and a small blood transfusion was given. At 80 hours of age a Dextrostix test showed a zero blood glucose concentration, and the infant developed a cardiac arrest and could not be resuscitated, During the course of the last 12 hours the prog thrombin time and partial thromboplastin time were prolonged. The platelet count fell to $141 \times 10^{9} / 1$ bu位 no fibrin degradation products could be found. The serum urea concentration rose to $6.8 \mathrm{mmol} / \mathrm{l}$ and the potassium concentration to $6.7 \mathrm{mmol} / \mathrm{l}$. Cultures of blood samples were negative.

At necropsy 30 hours after death the brain was congested but showed no subependymal haemorrhage. The heart was normal with a patent ductus arteriosus. The lungs were uniformly dark red and solid. The jejunum and ileum were dilated and purple with focal thinning of the wall and fibrinous exudate on the serosa, typical of necrotising enterocolitis. Focal ulcers were seen in the colonic mucosa but there were no perforations. The other organs appeared to be normal.

\section{CASE 2}

A baby girl born after 39 weeks' gestation was delivered by emergency caesarian section because of $\Omega$ unsuspected placenta praevia presenting with vaginal $N$ haemorrhage and fetal bradycardia. At delivery the infant weighed $348 \mathrm{~g}$, and Apgar scores were 0 at one minute, 0 at five minutes, and 2 at 10 minutes. She

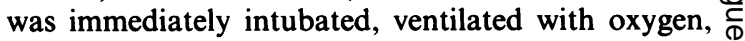
and given sodium bicarbonate, adrenalin, and cardiac $\stackrel{\mathscr{P}}{+}$ massage. Shortly afterwards spontaneous breathing 7 started but the heart rate was less than 100 /minute 


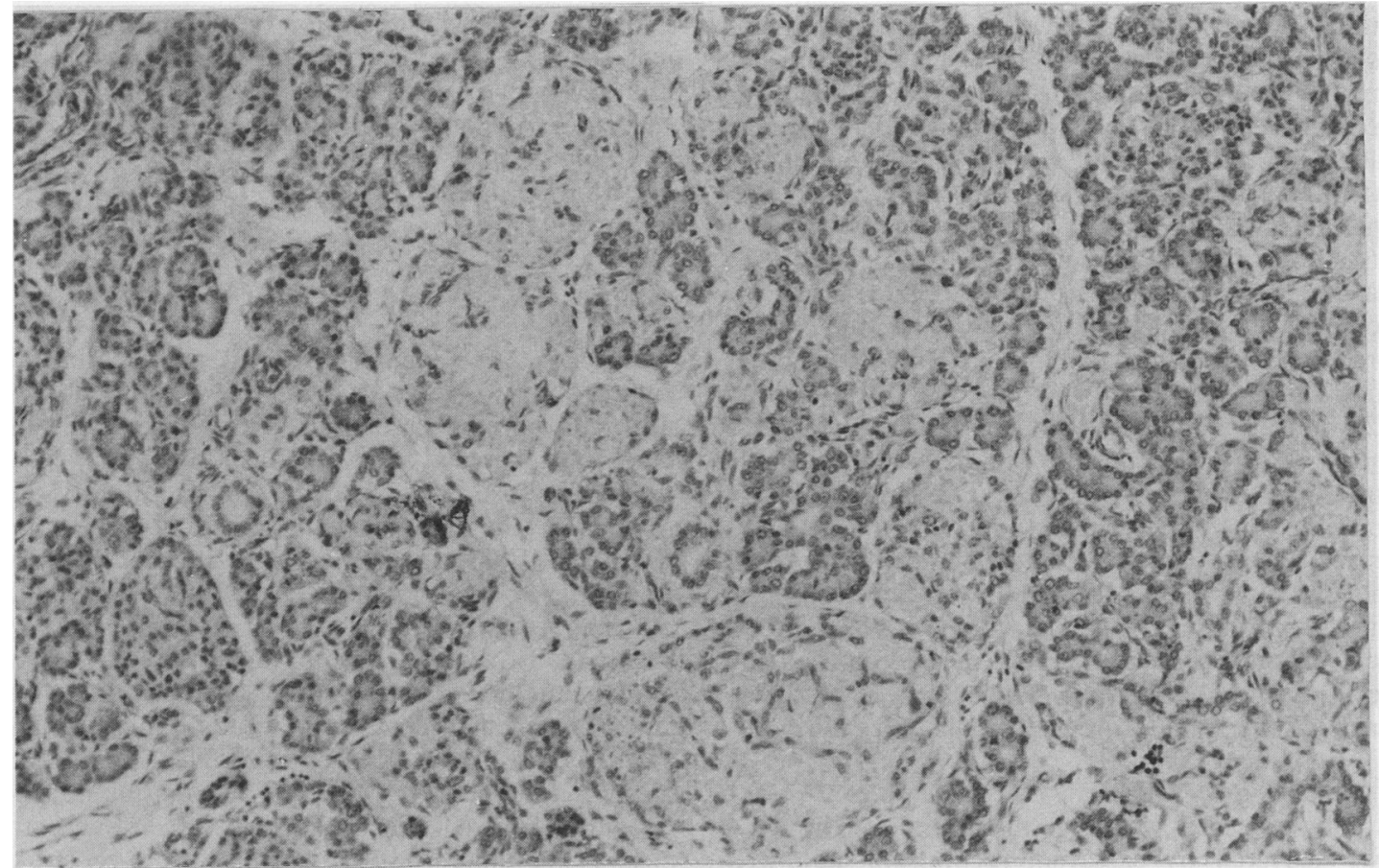

Fig 1 At least eight necrotic islets within acinar tissue of pancreas. (Haematoxylin and eosin.)

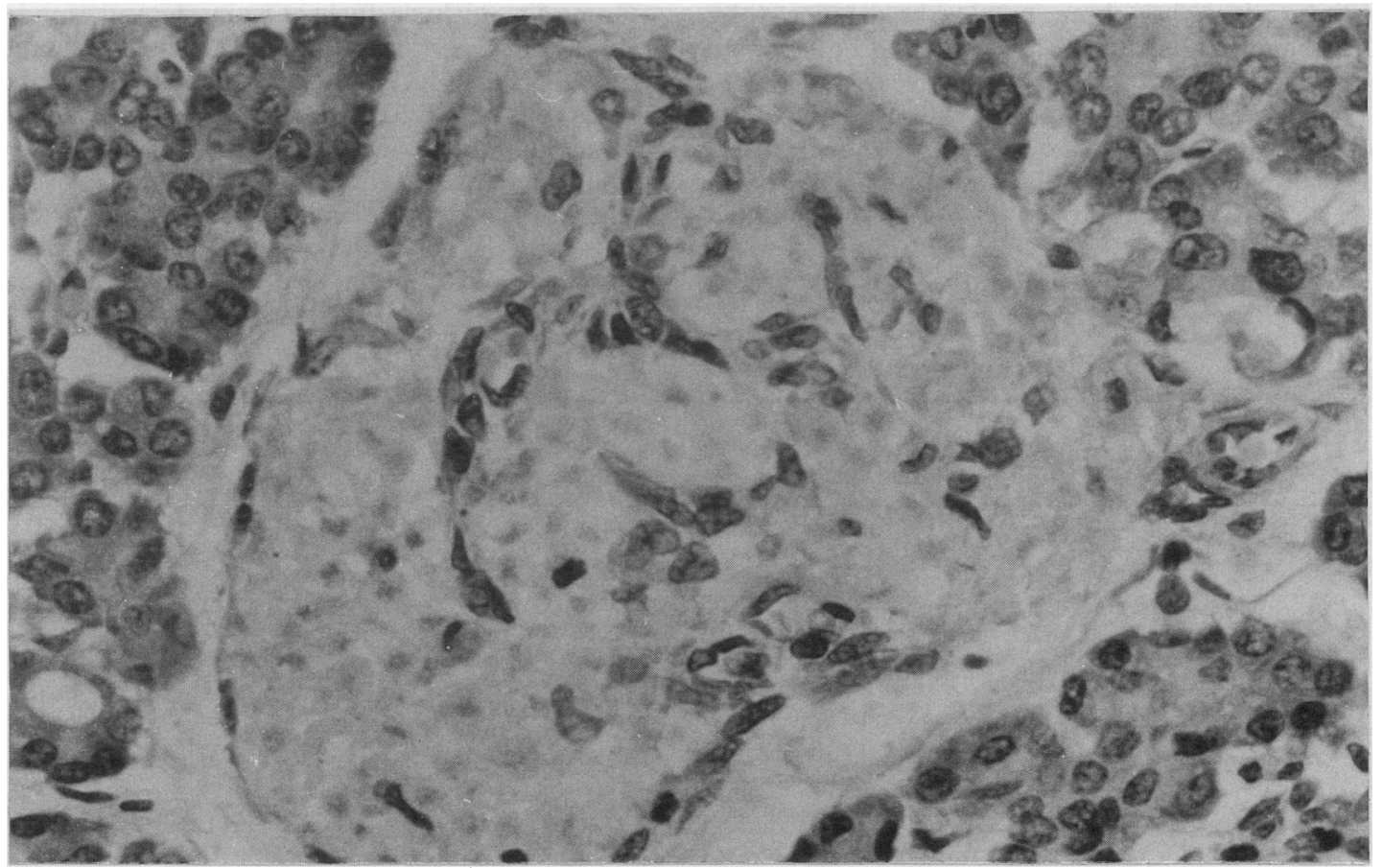

Fig 2 Detail of necrotic islet to show eosinophilic necrosis of cells with ghost like remains of nuclei and residual viable endothelial cells. (Haematoxylin and eosin.) 
and a Dextrostix test showed a zero blood glucose concentration. Four mls of $50 \%$ dextrose with dexamethasone, blood transfusion, and frusemide were given. At two hours the blood pressure fell, the heart rate dropped to $60 /$ minute, and she was reintubated. At six hours convulsions developed and were treated with phenobarbitone. Hypotension persisted and at 16 hours of age she died. Investigations included: haemoglobin concentration of $9.0 \mathrm{~g} / \mathrm{dl}$, white cell count of $8.6 \times 10^{9} / 1$, platelets at $94 \times 10^{9} / 1$, serum urea concentration of $1.7 \mathrm{mmol} / \mathrm{l}$, and serum potassium concentration of $4.7 \mathrm{mmol} / \mathrm{dl}$. At necropsy 72 hours after death, the brain showed no evidence of intracerebral haemorrhage. The lungs were pale and solid with some purulent material in the bronchi and trachea. The heart was pale with a patent ductus arteriosus. The stomach showed haemorrhages in the mucosa, and the small bowel was bluish-red with blood-stained contents. The colon was normal; no perforation was seen. The liver showed mottled congestion, and the adrenal glands showed segmental areas of haemorrhage. Other organs were normal.

\section{CASE 3}

A baby boy of 37 weeks' gestation and weight $3060 \mathrm{~g}$ was delivered by caesarian section for failure of labour to progress and was found to have short limbed dwarfism (spondylo-epiphyseal dysplasia congenita), which had been previously diagnosed by ultrasound scan. The ribs and vertebral bodies were poorly calcified, soft, and compressible and there was a pronounced reduction in chest volume. At birth the Apgar score was 7-8 and oxygen was required to keep the skin pink. In view of the poor prognosis oxygen was discontinued at two hours of age and he died aged 12 hours.

At necropsy six days after death, the brain showed anoxic changes with dilatation of superficial capillaries. The lungs were blue, solid, and poorly aerated, and the ribs were softened and showed bulbous costal cartilages. The chest volume was reduced. The heart and great vessels were normal. The intra-abdominal viscera were normal.

\section{Microscopic features}

\section{CASE 1}

The colon and ileum showed an acute ischaemic enterocolitis with gas cysts in the submucosa, and fibrin thrombi in capillaries. No evidence of Hirschsprung's disease was seen. The kidney showed no tubular necrosis. The liver, heart, adrenals, testis and thymus showed anoxic haemorrhages but no necrosis. Fibrin thrombi were seen in splenic trabecular vessels. The lungs showed anoxic alveolar and septal haemorrhage and fibrin thrombi in pulmonary artery branches. No hyaline membrane was present. The brain contained a microscopic subependymal haemorrhage in the region of the caudate nucleus. The pancreas showed no abnormality of the exocrine elements but about half (estimated by counting islets in sections from each block) of the islets showed complete eosinophilic necrosis, leaving only a ghost-like outline of the pre-existing endocrine cell cytoplasm and nucleus (figs 1 and 2).

Gomori's aldehyde fuchsin stain showed smudg granules of B cells in the necrotic islets. No immue noglobulin (IgM, IgG, IgA) deposits were detected in the islet cells or in the capillary walls using a standard peroxidase-antiperoxidase method (Dakopatts) on paraffin sections. In about one tenth of the overall number of islets there was incomplete necrosis characterised by pyknosis and karyorrhexis of nuclei and eosinophilia of cytoplasm. No viral inclusion bodies

Table Details of cases reported to date

\begin{tabular}{|c|c|c|c|c|}
\hline Source & Gestation (weeks) & Maternal factors & Delivery & Weight $(g)$ \\
\hline 1 & 40 & Prolonged labour & Cephalic vaginal & 2994 \\
\hline 2 & 42 & Post-mature & Vertex vaginal & 3402 \\
\hline 3 & 36 & Placenta praevia rhesus incompatability & Caesarian & 2608 \\
\hline 4 & 37 & Road traffic accident & Caesarian & 3000 \\
\hline 5 & 40 & Ante-partum haemorrhage & Caesarian & Not known \\
\hline 6 & 12 weeks post-partum & Down's syndrome & Not known & Not known \\
\hline 7 & 35 & Ante-partum haemorrhage toxaemia & Caesarian & 2044 \\
\hline 8 & 39 & Ante-partum haemorrhage vasa praevia & Caesarian & 3480 \\
\hline 9 & 37 & Prolonged labour & Caesarian & 3066 \\
\hline
\end{tabular}




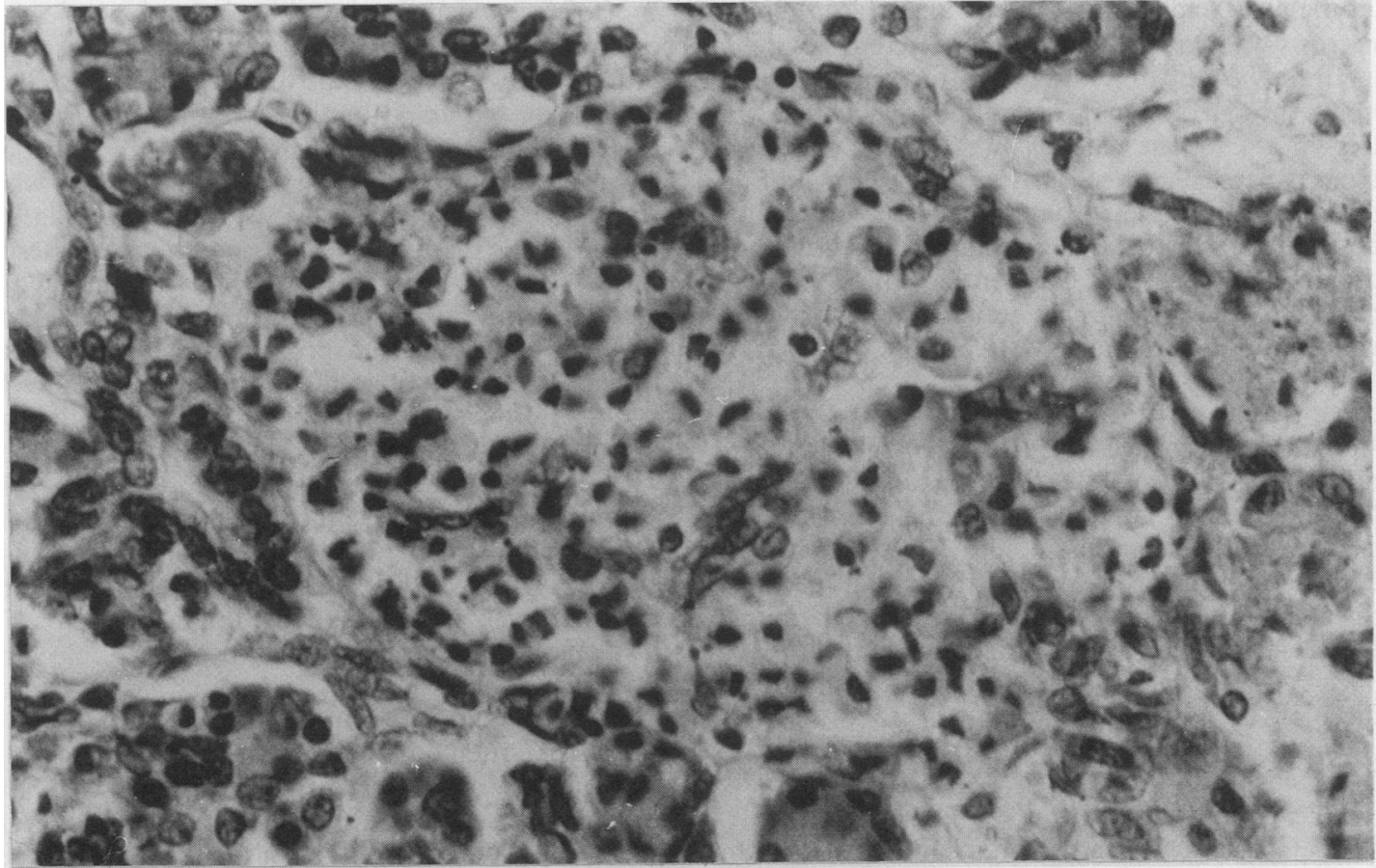

Fig 3 Another islet showing incomplete necrosis with pyknotic, irregular nuclei and shrinkage of cytoplasm. Changes are particularly noticeable in left hemisphere. (Haematoxylin and eosin.)

were seen in the endocrine cells. The nuclei of these degenerate cells was often spindle or wedge shaped and as small as half the size of nearby unaffected islet cells. The cytoplasm was similarly reduced in amount (fig 3). These degenerative changes were present throughout the pancreas but the severity of the changes seemed to be relatively uniform within lobules of pancreatic tissue.

The capillary network of the islets was intact with viable plump endothelial cells lining congested vascu- lar channels which were free of fibrin thrombi. There was no exudation of fibrin in the islets and no inflammatory reaction. Pancreatic interlobular veins were dilated. No thrombi or interstitial haemorrhages were seen in the exocrine tissue and no autolysis was present.

\section{CASE 2}

The ileum showed acute infarction with early necrosis of mucosa. Focal haemorrhagic congestion was seen

\begin{tabular}{|c|c|c|c|c|c|c|}
\hline \multirow{2}{*}{$\begin{array}{l}\text { Age at death } \\
\text { (hours) }\end{array}$} & \multirow[b]{2}{*}{ Apgar score } & \multirow[b]{2}{*}{ Intravascular coagulation } & \multicolumn{4}{|c|}{ Microscopical ischaemic necrosis } \\
\hline & & & Renal & Hepatic & Intestinal & Adrenal \\
\hline $8 \cdot 5$ & Not done & Not known & + & + & - & + \\
\hline 9 & Not done & Not known & + & + & - & - \\
\hline $11 \cdot 5$ & Not done & Not known & + & + & + & + \\
\hline 48 & Not done & No & + & + & + & - \\
\hline 26 & 0 (1 min), 1 (5 mins) & No & + & + & - & - \\
\hline 72 & Not done & No & + & + & - & - \\
\hline 92 & $8(1 \mathrm{~min}), 9(5 \mathrm{~min})$ & Yes & - & - & + & - \\
\hline 16 & $0(1 \mathrm{~min}), 0(15 \mathrm{~min})$ & Yes & - & - & + & - \\
\hline 12 & $7(1 \mathrm{~min}),-(5 \mathrm{~min})$ & No & - & - & - & - \\
\hline
\end{tabular}


in the liver, adrenals, kidneys and spleen but no necrosis was present, though there were fibrin deposits in the hepatic and adrenal cortical sinusoids. The lungs showed amniotic aspiration due to fetal distress. The exocrine pancreas was normal. The endocrine pancreas showed early necrosis in a little less than half of the islets, characterised by nuclear pyknosis and karyorrhexis and eosinophilic degeneration of cytoplasm. About one tenth showed complete necrosis. The appearances were otherwise identical with those of case 1 .

\section{CASE 3}

Anoxic haemorrhages were seen in the thymus and renal cortex and medulla. Fetal squames were seen in lung alveoli. No adrenal haemorrhage or ischaemic changes in the ileum and colon were seen. The pancreas showed normal exocrine tissue, but about one third of the islets showed eosinophilic degeneration of the cell cytoplasm with partial or complete loss of nuclei. The appearances were otherwise identical with those of case 1 .

\section{Discussion}

Neonatal islet cell necrosis in the absence of frank pancreatitis, tumour or viral ${ }^{45}$ infections such as Coxsackie B5, Rubella, cytomegalovirus, and varicella-zoster, is a rarely reported phenomenon. Only three previous reports document the condition. The first by Bernstein ${ }^{1}$ in 1958 described three neonates who developed anoxia in the perinatal period and died within 32 hours of birth. One neonate was premature and the other two were term deliveries. The islet cell necrosis was associated with renal tubal necrosis in each case. Morphologically, the islets showed the same histological appearance as the three cases reported here. The exocrine tissue was unaffected. No blood sugar concentrations were recorded, although all three neonates had terminal convulsions alternating with periods of flaccidity. The second report by Emery and Bury ${ }^{2}$ described a survey of 1000 necropsies on infants and children, of which 40 showed haemorrhagic "lesions" of the islets consisting of dilated sinusoids and collapse and loss of islet cell cytoplasm with pyknosis of the nuclei. These cases resemble the early stages of my three examples of complete necrosis of the islet cells. Curiously, Emery and Bury recognised the "occasional case" in which there was complete coagulative necrosis of the islets but failed to describe or include the cases in their survey. No blood sugar concentrations were recorded in the affected infants. Their patients with islet haemorrhagic lesions were stillborn or neonates surviving up to 28 days of age. There was a positive association with prematurity and stillbirth,
$75 \%$ of cases occurring in stillbirths, and over $75 \%$ of cases occurring in neonates of less than 37 weeks' gestation. The oldest case was found as late as 28 days after birth. No association was found with cyanotic attacks, convulsions, hyaline membrane disease, haemorrhagic manifestations or maternal diabetes when compared with other infants dying at the same age. In the stillbirths there was no association with maternal toxaemia or hypertension. The third report ${ }^{3}$ described three infants ranging in age from 1 day to 3 months; two died from profound shock in a road traffic accident and placental abruption, respectively, and the third from congenital heart disease with heart failure. The morphological features were identical with those of the three cases reported here. The authors reviewed 30 other neonatal and infant necropsies in which there was clinical or morphological evidence of shock and they were unable to find any additional examples of islet cell necrosis.

Excluding Emery and Bury's cases, the table summarises the salient features of the nine cases reported to date. There is a common clinical picture of anoxia and shock, often due to maternal factors such as placental abruption. Two thirds of the infants were born by caesarian section and none was less than 35 weeks gestation. Over half were born at full term. In each case the birth weight was consistent with the length of gestation, and no clinically important growt $B$ retardation can have occurred. Microscopical exam ination of other organs showed a variety of lesion⿳亠丷厂 associated with shock. No common pattern of tissue damage could be identified, though renal tubular necrosis and central hepatic necrosis were most often associated.

It could be that the islet changes were attributable to post mortem autolysis. In the three cases reported here the necropsies were performed 30,72 hours, and six days after death, the bodies having been refrigerated almost immediately. The tissues were well preserved in all three cases, even after six days. Furthermore, the proportion of islets showing necrotic change was inversely related to the interval after death; autolysis therefore seems to be an unlikely explanation for these changes.

Hypoglycaemia was detected in two of the cases currently described but was not estimated in the third. In the other two series the serum glucose concentration was not measured. No common pattern of drug ingestion or injection was seen in the mothers of the three cases I reported, either during pregnancy or in labour. The hypoglycaemia may have been a direct result of the extensive islet cell necrosis leading to sudden release of insulin from the damaged cells. Such a mechanism is well recognised in the early phase of diabetes mellitus ${ }^{6}$ induced by the experimental use of alloxan. 
Haematological and microscopical evidence of disseminated intravascular coagulation was detected in two of my cases but it was not seen in Seemayer's cases and it was not looked for in Bernstein's series.

Emery and Bury's large scale survey of 1000 necropsies on infants and children showed an incidence of $4 \%$ of haemorrhagic lesions in the islets. The lesions they describe are similar to those described in this paper and may represent an early phase in development of frank necrosis. While an association with prematurity was noted, they were unable to find a consistent link with any clinical features or any histological changes in other organs. Similarly, those cases discovered in stillbirths were unassociated with any maternal factors which may have caused intrauterine anoxia. They concluded that the islet changes were physiological rather than pathological and represented a form of involution during development. Further support for this hypothesis is seen in Seemayer's paper where he reviews 30 cases of fatal shock in infancy and fails to find additional examples of islet cell necrosis. He cites this finding, however, to support his contention that the condition is a rare manifestation of shock rather than to suggest an alternative mechanism for its development.

Additional support for a physiological mechanism for cell necrosis can be found in the modern concept of apoptosis. ${ }^{7}$ The combination of eosinophilic necrosis of cytoplasm, shrinkage, and pyknosis of nuclei, and lack of inflammatory response are the light-microscopical hallmarks of apoptosis. Physiological apoptosis is well recognised in the fetal adrenal cortex, endometrium, female breast and corpus luteum; perhaps this is what we have been describing in the islets of Langerhans.

Two conflicting theories on the development of these lesions remain. The first is that neonatal shock leads to reduced haemoperfusion or anoxia which causes selective necrosis of the islets. This necrosis does not affect the exocrine tissue even though it shares a common anatomical blood supply. The higher metabolic requirements of the islet tissue in response to shock may explain this phenomenon. The second is that the necrosis is a florid physiological process akin to apoptosis and the presence of shock or anoxia is purely coincidental. On the evidence so far, neither theory can be confidently substantiated. It is difficult, however, to believe that a physiological phenomenon could lead to such widespread destruction of endocrine cells. Furthermore, Seemayer cites personal unpublished evidence of experimental, hypovolaemic induced necrosis of pancreatic islets in young rats. It is only by wider recognition of this entity and further studies that progress can be made into the understanding of this rare condition.

\section{References}

1 Bernstein J. Renal tubular and pancreatic islet cell necrosis in newly born infants. Am J Dis Child 1958;96:705-10.

2 Emery JL, Bury HPR. Involuntary changes in the islets of Langerhans in the foetus and newborn. Biol Neonate 1964;6:16-25.

2 Seemayer TA, Osborne C, De Chadarevian JP. Shock related injury of pancreatic islets of Langerhans in newborn and young infants. Hum Pathol 1985;16:1231-4.

4 Jenson AB, Rosenberg HS, Notkins AL. Pancreatic islet cell damage in children with fatal viral infections. Lancet 1980;ii:354-8.

5 Ahmad M, Abraham AA. Pancreatic ileitis with coxsackie virus B5 infection. Hum Pathol 1982;13:661-2.

6 Howel SL, Taylor KW. The acute pancreatic effect of Alloxan in the rabbit. J Endocrinol 1967;37:421-7.

7 Kerr JFR, Bishop CJ, Searle J. Apoptosis. In: Recent advances in histopathology, 12. Edinburgh: Churchill Livingstone, 1985:1-15.

Requests for reprints to: Dr PF Roberts, Consultant Histopathologist, Norfolk and Norwich Hospitals, Brunswick Road, Norwich, Norfolk NR1 3SR, England. 